\title{
DETECTION OF JAK-2 MUTATION BY PCR TECHNIQUE IN CHRONIC MYELOPROLIFERATIVE DISORDERS
}

\author{
Mervat M. Azab, Nadia A. Albaz, Foaad M. Abotaleb* and Abdel-Rahman A. Naeem, \\ Clinical pathology and Medical oncology* departments; Zagazig university hospitals, Egypt.
}

\begin{abstract}
At this study we aimed to detect the prevalence of JAK2 V617F mutation in various myeloproliferative neoplasms (MPNs) that represent a major advance in molecular understanding of CMPN disorders in order to identify its diagnostic value.

In this study we evaluated it's clinical and laboratory correlates in 40 patients with MPNs. The mutation was detected by allele-specific PCR.

The mutation was detected in 8 patients: $80 \%$ (8/10) of those with polycythemia vera, $63.6 \%(7 / 11)$ of those with essential thrombocythemia, $62.5 \%(5 / 8)$ of those with chronic idiopathic myelofibrosis and $0 \%(0 / 11)$ of those with chronic myeloid leukemia. The patients carrying the mutation were older $(p=0.003)$ and have splenomegaly in polycythemia vera group $(\mathrm{p}=0.05)$ but no statistical difference was found between positive and negative JAK2 carriers as regarding HB, TLC ,PLTs count or gender type $(\mathrm{P}>0.05)$.

This study implies that the JAK2-V617F mutation may be useful for the diagnosis, classification and the management of patients with MPDs.

Keywords: JAK2 V617F; Polycythemia vera; Essential thrombocythemia; chronic Idiopathic myelofibrosis; Myeloproliferative neoplasms.
\end{abstract}

\section{INTRODUCTION}

$\mathrm{C}$ hronic myeloproliferative Neoplas-ms (CMPNs) are clonal hematopoietic stem cell disorder characterized by proliferation of one or more myeloid cell lineage in the bone marrow and increased number of mature and immature cells in the peripheral blood.

CMPNs include polycythemia Vera (PV), esssential thrombocythemia (ET), chronic idiopathic myelofibrosis (CIMF) and chronic myeloid leukemia (CML), plus rare types such as chronic neutrophilic leukemia (CNL), hyperesinophilic syndrome (HES) and chronic esinophilic leukemia (CEL). There are other disorders overlap with both myeloproliferative and myelodysplastic disorders and classified as (MDS/MPN) such as atypical CML (aCML), chronic myelomonocytic leukemia (CMML) and juvenile myelomonocytic leukemia(JMML) in which proliferation is accompanied by dysplastic features of ineffective hematopoiesis in other lineages. [1]

Although there are strict diagnostic criteria for MPN subtypes, precise categorization remains a subject of debate and furthermore, it is difficult to differentiate some cases from reactive disorders. Only CML is characterized by a pathognomonic molecular marker, the breakpoint cluster regionAbelson (BCR-ABL) fusion gene which is a constitutively activate tyrosin kinase that is believed to be the primary and probably the only driving force behind chronic phase CML. The primary abnormalities driving excess proliferation in most other cases have been obscure. However, several lines of evidence have implicated aberrant tyrosin kinase have been identified in some cases of aCML, CMML, and HES/CEL such as platelets derived growth factor receptor alpha (PDGFRA), platelets derived growth factor receptor beta (PDGFRB), fibroblast growth factor receptor 1 (FGFR1), and the recently diagnosed JanusKinase 2 (JAK2) genes. [2]

The Jak2-V617F mutation causes substitution of Phenylalanine for Valine at position 617 of the Jak2 gene. This mutant Jak2 has enhanced kinase activity and when expressed with the presence of erythropoietin receptor in cells it causes hyperactivation of erythropoietin induced cell signaling. [3]

The molecular pathogenesis of BCR-ABL negative MPNs was poorly understood until the identification of JAK2 V617F mutation. The identification of JAK2 V617F in PV, ET, CIMF and other MPNs may represent an important advance in our understanding of the myeloproliferative neoplasms. [4]

\section{MATERIAL AND METHODS}

\section{Patients}

This study included 10 healthy subjects as control group and 40 patients with newly diagnosed MPNs; 10 with PV, 11 with ET, 8 with MF and 11 with CML. These patients were referred from hematology outpatient clinic to different laboratories of zagazig university hospitals between December 2011 and June 2013. Patients were subjected to complete history taking and general medical examination The following laboratory Investigations were done CBC BM. Smear and biopsy BCR-ABL fusion gene by PCR technique to diagnose CML cases and detection of JAK2 mutation by Allele specific PCR technique. 
Formed consents were obtained from every healthy control and patient before sampling.

2.2. Allele-specific PCR for the detection of JAK2-V617F mutation

The JAK2-V617F mutation was detected according to the protocol of Baxter et al,. (2005) [5] with some modifications. the primers used for multiplex PCR were

J1 (reverse):

5

CTGAATAGTCCTACAGTGTTTTCAGTTTCA -3 ,

$\mathrm{J} 2$ (forward specific):

5

AGCATTTGGTTTTAAATTATGGAGTATATT -3 ,

and J3 (forward-internal control):

\section{5_-}

ATCTATAGTCATGCTGAAAGTAGGAGAAA G-3.

We added 1 ul of each diluted (1:3) primer and 3 ul extracted DNA and 21 ul D.W. to master-mix tube and put the mix tube in thermal cycler for 2 $\min$ at $94{ }^{\circ} \mathrm{C}$ followed by 35 cycles each cycle was performed at $94{ }^{\circ} \mathrm{C}$ for $45 \mathrm{~s}, 59{ }^{\circ} \mathrm{C}$ for $45 \mathrm{~s}$, $72{ }^{\circ} \mathrm{C}$ for $60 \mathrm{~s}$ then after all cycles the tube was incubated for $5 \mathrm{~min}$ at $72{ }^{\circ} \mathrm{C}$ after the last cycle. The PCR products were analyzed on $2 \%$ agarose gels. The primers J1 and J3 amplify a $364 \mathrm{bp}$ product (both mutant and wild-type alleles and serves as an internal control), while the primers J1 and $\mathrm{J} 2$ amplify a $203 \mathrm{bp}$ product (when the patient carries the JAK2-V617F (Fig.1)

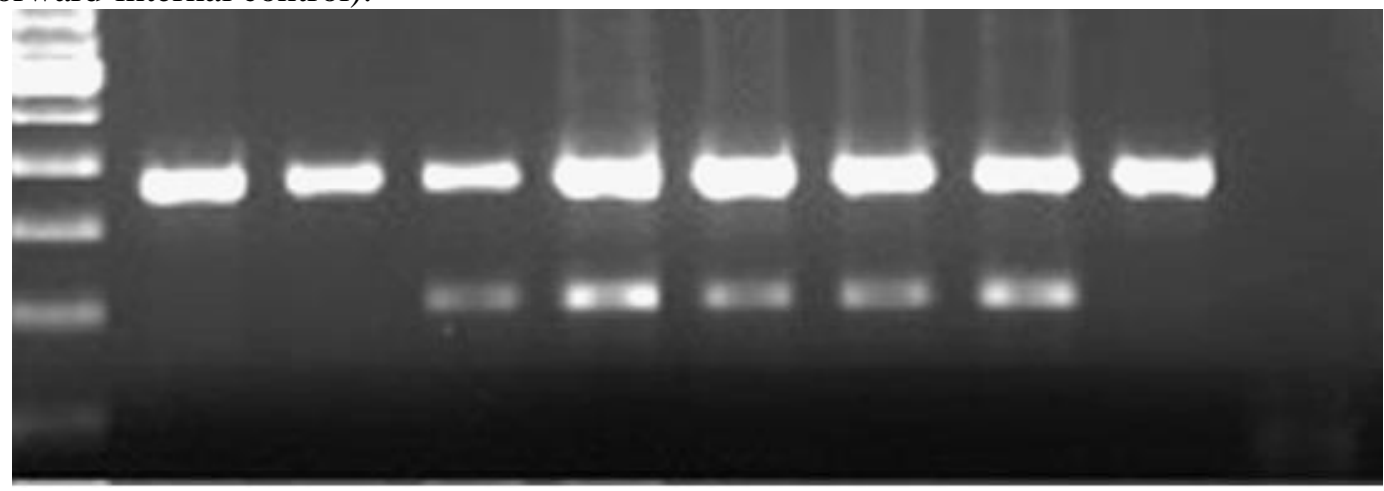

Fig.1: JAK2-V617T mutation established by allele-specific PCR. An allele-specific PCR protocol was performed amplifying a 364 bp product (both mutant and wild-type alleles and serves as an internal control) and a 203 bp product (when the patient carries the JAK2-V617F mutation).

\subsection{Statistical analysis}

The comparison between positive and negative carriers for JAK2 mutation as regarding quantitative parameters ( $\mathrm{Hb}$, TLC and PLTs count) was performed by independent sample TTest, while the association of JAK2 mutation with non quantitative parameters as (gender and splenomegaly) was performed using chi- square test. Also ANOVA was performed to compare quantitative parameters among different groups.The associations was expressed with the corresponding 95\% confidence interval (CI). A variable was considered significant when $p \leq 0.05$. The analysis was performed using IPM SPSS Version 20.

\section{RESULTS}

\subsection{Prevalence of JAK2-V617F mutation} in patients with MPNs

Twenty patients out of 40 patients $(50 \%)$ were positive for the presence of the JAK2-V617F mutation. More specifically, the prevalence of mutation in the different subtypes of MPNs was $80 \%$ in PV (8 out of 10 patients), $63.6 \%$ in ET (7 out of 11 patients), $62.5 \%$ in IMF (5 out of 8 patients) and $0 \%$ in CML ( 0 out of 11 patients) . Characteristics of the patients are shown in Table 1 , which also displays the information according to JAK2-V617F mutational status. In all cases, allele-specific PCR was performed.

3.2. Correlations of JAK2-V617F mutation with clinical and laboratory findings in MPNs patients

Statistical comparison between positive and negative Jak2 mutation in PV, ET and MF groups revealed non significant difference as regarding Plts count, TLC and $\mathrm{Hb}$ concentration, but high significant difference as regarding age whith older age in positive Jak2 mutation group. Also there was no significant relation between splenomegaly or gender and positive mutation CMPN group. Tables $[1,2]$ 
Table 1: comparison between positive and negative Jak2 mutation groups as regarding various data

\begin{tabular}{|c|c|c|c|c|c|c|c|}
\hline \multicolumn{8}{|c|}{ CMPNs } \\
\hline & Jak2 & $\mathrm{N}$ & Mean & St.d & $\mathrm{T}$ test & Sig. & \\
\hline \multirow{2}{*}{ Age } & +ve & 20 & 47.3 & 8.84 & 3.23 & 0.003 & HS \\
\hline & -ve & 9 & 35.8 & 9.05 & & & \\
\hline \multirow{2}{*}{ HB } & $+\mathrm{ve}$ & 20 & 14.3 & 5.6 & 1.09 & 0.285 & NS \\
\hline & -ve & 9 & 11.97 & 4.5 & & & \\
\hline \multirow{2}{*}{ TLC } & +ve & 20 & 10.7 & 4.4 & -.408 & 0.687 & NS \\
\hline & -ve & 9 & 11.7 & 8.8 & & & \\
\hline \multirow{2}{*}{ PLTs } & +ve & 20 & 610 & 409.3 & 0.162 & 0.872 & $\mathrm{NS}$ \\
\hline & -ve & 9 & 584 & 363.3 & & & \\
\hline
\end{tabular}

Table 2: relations between JAK2 presentation and splenomegaly and gender

\begin{tabular}{|c|c|c|c|c|c|}
\hline & Jak2 +ve & Jak2 -ve & Chi square & $\mathrm{P}$ value & Sig. \\
\hline CMPN +ve spleen & 16 & 5 & \multirow[t]{2}{*}{1.86} & \multirow[t]{2}{*}{0.173} & \multirow[t]{2}{*}{$\mathrm{NS}$} \\
\hline CMPN -ve spleen & 4 & 4 & & & \\
\hline$\overline{\text { CMPN Male }}$ & 12 & 4 & \multirow[t]{2}{*}{0.607} & \multirow[t]{2}{*}{0.436} & \multirow[t]{2}{*}{$\overline{N S}$} \\
\hline CMPN Female & 8 & 5 & & & \\
\hline CMPN no. & 20 & 9 & & & \\
\hline PV +ve spleen & 6 & 0 & \multirow[t]{2}{*}{3.75} & \multirow[t]{2}{*}{0.05} & \multirow[t]{2}{*}{ Sig. } \\
\hline PV -ve spleen & 2 & 2 & & & \\
\hline PV male & 5 & 1 & \multirow[t]{2}{*}{0.104} & \multirow[t]{2}{*}{0.747} & \multirow[t]{2}{*}{$\overline{N S}$} \\
\hline PV female & 3 & 1 & & & \\
\hline PV no. & 8 & 2 & & & \\
\hline ET +ve spleen & 5 & 2 & \multirow[t]{2}{*}{0.505} & \multirow[t]{2}{*}{0.477} & \multirow[t]{2}{*}{$\overline{\mathrm{NS}}$} \\
\hline ET -ve spleen & 2 & 2 & & & \\
\hline ET male & 3 & 2 & \multirow[t]{2}{*}{0.052} & \multirow[t]{2}{*}{0.819} & \multirow[t]{2}{*}{$\overline{N S}$} \\
\hline ET female & 4 & 2 & & & \\
\hline ET no. & 7 & 4 & & & \\
\hline MF +ve spleen & 5 & 3 & \multirow{2}{*}{\multicolumn{2}{|c|}{$\begin{array}{l}\text { All cases have splenomegaly } \\
\text { (non statistic) }\end{array}$}} & \\
\hline MF -ve spleen & 0 & 0 & & & \\
\hline MF male & 4 & 1 & \multirow[t]{2}{*}{1.74} & \multirow[t]{2}{*}{0.187} & \multirow[t]{2}{*}{$\mathrm{NS}$} \\
\hline MF female & 1 & 2 & & & \\
\hline MF no. & 5 & 3 & & & \\
\hline
\end{tabular}

\subsection{Prevalence and correlations of JAK2-} V617F mutation in patients with ET

Statistical comparison between positive and negative Jak2 mutation in ET group revealed non Significant difference As regarding Plts
count,TLC and $\mathrm{Hb}$ concentration and age. Also there was no relation between gender and splenomegaly in ET and JAK2 expression. Tables $[2,3]$ 
Table 3: comparison between positive and negative Jak2 mutation in ET group as regarding various data

\begin{tabular}{|c|c|c|c|c|c|c|c|}
\hline \multicolumn{8}{|c|}{ Group Statistics } \\
\hline & ET.jak2 & $\mathrm{N}$ & Mean & St.d & $\mathrm{T}$ test & Sig. & \\
\hline \multirow{2}{*}{ Age ET } & $+\mathrm{ve}$ & 7 & 44.14 & 6.04 & 1.76 & 0.111 & NS \\
\hline & -ve & 4 & 37.50 & 5.912 & & & \\
\hline \multirow{2}{*}{ hb. ET } & $+\mathrm{ve}$ & 7 & 11.40 & 1.47 & 1.504 & 0.167 & NS \\
\hline & -ve & 4 & 10.00 & 1.53 & & & \\
\hline \multirow{2}{*}{ tlc. ET } & +ve & 7 & 9.79 & 3.14 & 1.43 & 0.188 & NS \\
\hline & -ve & 4 & 16.18 & 11.59 & & & \\
\hline \multirow{2}{*}{ plt. ET } & +ve & 7 & 1065.0 & 279 & 0.95 & 0.413 & NS \\
\hline & -ve & 4 & 928.25 & 196 & & & \\
\hline
\end{tabular}

\subsection{Prevalence and correlations of JAK2-} V617F mutation in patients with $P V$

Statistical comparison between positive and negative Jak2 mutation in PV group revealed highly significant difference between positive and negative PV patients as regarding age With higher age in positive jak2 patients but non Significant difference was found as regarding Plts count, TLC and $\mathrm{Hb}$ concentration. Also there was significant relation between splenomegaly and positive mutation in PV. and no relation between was found between gender and JAK2 expression in PV group. Tables $[2,4]$

3.5. Prevalence and correlations of JAK2 V617F mutation in patients with CIMF

Statistical comparison between positive and negative Jak2 mutation in CIMF group revealed non significant difference as regarding Plts count, TLC and $\mathrm{Hb}$ concentration and age. Also there was no relation between gender and splenomegaly in CMPNs and JAK2 expression. Tables [2,5]

Table 4: comparison between positive and negative Jak2 mutation in PV group as regarding various data

\begin{tabular}{|c|c|c|c|c|c|c|c|}
\hline \multicolumn{8}{|c|}{ Group Statistics } \\
\hline & pv.jak2 & $\mathrm{N}$ & Mean & St.d & $\mathrm{T}$ test & Sig. & \\
\hline \multirow[t]{2}{*}{ HB. PV } & $+\mathrm{ve}$ & 8 & 20.46 & 2.56 & 0.834 & 0.663 & $\mathrm{NS}$ \\
\hline & -ve & 2 & 19.60 & 0.707 & & & \\
\hline \multirow[t]{2}{*}{ PV. age } & $+\mathrm{ve}$ & 8 & 54.50 & 7.05 & 4.99 & 0.001 & $\mathrm{HS}$ \\
\hline & -ve & 2 & 25.50 & 9.19 & & & \\
\hline \multirow[t]{2}{*}{ TLC. PV } & $+\mathrm{ve}$ & 8 & 14.5 & 2.585 & 1.49 & 1.75 & NS \\
\hline & -ve & 2 & 11.45 & 2.616 & & & \\
\hline \multirow[t]{2}{*}{ PLT. PV } & $+\mathrm{ve}$ & 8 & 503.12 & 92.2 & 1.76 & 0.116 & NS \\
\hline & -ve & 2 & 374.50 & 94.04 & & & \\
\hline
\end{tabular}

Table 5: comparison between positive and negative Jak2 mutation in CIMF group as regarding various data

\begin{tabular}{|c|c|c|c|c|c|c|c|}
\hline \multicolumn{8}{|c|}{ Group Statistics } \\
\hline & MF.jak2 & $\mathrm{N}$ & Mean & St.d & $\mathrm{T}$ test & Sig. & \\
\hline \multirow{2}{*}{ Age MF } & +ve & 5 & 8.48 & 1.795 & 0.24 & 0.98 & $\mathrm{NS}$ \\
\hline & -ve & 3 & 9.5 & 0.62 & & & \\
\hline \multirow{2}{*}{ hb. MF } & $+\mathrm{ve}$ & 5 & 5.86 & 2.22 & 1.329 & 0.39 & $\mathrm{NS}$ \\
\hline & -ve & 3 & 5.833 & 3.61 & & & \\
\hline \multirow{2}{*}{ tlc. MF } & $+\mathrm{ve}$ & 5 & 143.8 & 84.95 & 0.13 & 0.990 & $\overline{\mathrm{NS}}$ \\
\hline & -ve & 3 & 265 & 179.9 & & & \\
\hline \multirow{2}{*}{ plt. MF } & $+\mathrm{ve}$ & 5 & 40.2 & 6.72 & 9.2 & 0.32 & $\mathrm{NS}$ \\
\hline & -ve & 3 & 40.33 & 9.5 & & & \\
\hline
\end{tabular}




\section{DISCUSSION}

We observed that the JAK2-V617F mutation was present in a high proportion of our MPNs patients and it was correlated with old age and splenomegaly. This agrees with Matthaios et al., (2006) [6] who found also correlation with higher $\mathrm{Hb}$ and low erythropoietin levels.

None of control group individuals $(0 \%)$ had Jak2 (V617F) mutation this agrees with (Amy et al., 2005) [2] who studied JAK2 mutation in 679 individuals from which 160 normal subjects as healthy controls and the other with MPNs, they did not found JAK2 mutation in any of their control cases. On the other hand; our results disagree with (Sidon et al., 2006) [7] who detect very low levels of JAK2 V617F mutation in 5 $(10 \%)$ of 52 clinically healthy individuals with unclear significance for these findings until now, Is follow up is recommended in positive healthy subjects, does it increase, and may mean prediction of new cases these remains questions.

In our study we detect JAK2 mutation in $50 \%$ of cases, in PV patients, 8 patients $(80 \%)$ had positive Jak2 mutation while 2 patients (20\%) had negative Jak2 mutation. In ET patients, 7 patients $(63.6 \%)$ had positive Jak2 mutation while 4 patients $(36.4 \%)$ had negative Jak2 mutation. In MF patients, 5 patients $(62.5 \%)$ had positive Jak2 mutation while 3 patients $(37.5 \%)$ had negative Jak2 mutation. The eleven cases of CML were negative for JAK2 mutation.

In this study, the frequency of Jak2 mutation among CMPNs was 50\% this is less than results of Kralovics et al., (2005) [8] who reported the prevalence of the mutation to be $66 \%$ but their study did not include CML. So if we exclude CML In our study Jak2 mutation will be (68.7\%) among PV, Et and MF and this agrees with them. In the current study, the frequency of Jak2 mutation among PV patients was $80 \%$ this is consistent with Matthaios et al., (2007) [6] Who found Jak2 mutation among PV patients to be $(81.4 \%)$, and also consistent with James et al., (2005) [9] who found the prevalence of Jak2 mutation in PV patients to be (89\%), while Baxter et al., (2005) [5] found it to be (97\%). So JAK2 $\mathrm{V} 617 \mathrm{~F}$ was considered as major criteria for diagnosis of PV according to WHO (2008). [10]

In our study, the frequency of Jak2 mutation among ET patients was $63.6 \%$ this agrees with Matthaios et al., (2007) [6] Who found Jak2 mutation among ET patients was $(69.3 \%)$ this also come in consistence with Baxter et al., (2005) [5] who found the prevalence of Jak2 mutation in ET patients to be (57\%). while Levine et al., (2006) [11] found it to be with lower frequency $(32 \%)$.
JAK2 V617F was considered as major criteria for diagnosis of ET according to WHO (2008). [10] In this study, the frequency of Jak2 mutation among MF patients was $62.5 \%$ this agrees with Matthaios et al., (2007) [6] Who found Jak2 mutation among MF patients in $(58.3 \%)$ this also come in consistence with Kralovics et al., (2005) [8] who found the prevalence of Jak2 mutation in MF patients to be (57\%), but contrary to Levine et al., (2005) [12] who detected lower frequency (32\%), Also JAK2 V617F was considered as Major criteria for diagnosis of CIMF according to WHO (2008). [10]

In our study there were $11 \mathrm{CML}$ cases 9 of them were typical with positive BCR-ABL fusion gene detected by PCR technique while 2 cases were atypical with negative BCR-ABL gene, but none of CML cases carried the JAK2 mutation.

The 2 Cases were considered as atypical CML because they did not have the criteria of CMML or JMML ( no monocytosis and not juvenile) and were negative for BCR-ABL by PCR. Atypical CML is beyond our scope of study as it is classified by WHO (2008) as MPN-MDS, so further investigation on atypical CML cases should be continued on larger scale to identify the percentage of atypical CML with positive JAK2 mutation or JAK2-PCM1 fusion as they were found in some cases of atypical CML. [13]

On comparing PV, ET and MF patients with control group, PV group revealed statistically significant difference as regarding age, Platelets count and $\mathrm{Hb}$ level with $\mathrm{p}$-value $(<0.05)$. This agrees Villeval et al., (2006) [14] who reported higher $\mathrm{Hb}$ level in PV. The ET group revealed statistically significant difference as regarding age, Platelets count and $\mathrm{Hb}$ level with p-value (< 0.05 ). While MF group revealed statistically significant difference as regarding age and lower $\mathrm{Hb}$ level with $\mathrm{p}$-value $(<0.05)$.

On comparison between positive Jak2 mutation $\mathrm{PV}, \mathrm{ET}$ and MF we found significant difference as regarding age, Platelets count, TLC and $\mathrm{Hb}$ level with $\mathrm{p}$-value $(<0.05)$. but non significant difference was found as regarding sex and splenomegaly. This agrees James et al., (2005) [9] who reported that positive Jak2 mutation PV has higher $\mathrm{Hb}$ levels than other positive mutation groups.

We found no significant difference between positive and negative JAK2 patients of CMPNs, $\mathrm{PV}, \mathrm{ET}$ and $\mathrm{MF}$ as regarding $\mathrm{Hb}$, Plts count, and TLC but there was significant difference between positive and negative JAK2 mutation groups as regarding age with higher age incidence in CMPNs patients and PV patients. 
Statistical relation between JAK2 V617F and both splenomegaly and gender type revealed significant relation between positive JAK2 mutation and splenomegaly in PV group only, on the other hand no relation between JAK2 mutation and spleen enlargement in all other groups. Also no relation was found between JAK2 mutation and sex type in all studied groups.

On comparing PV, ET and MF as regarding Jak2 mutation we found significant difference among groups with $\mathrm{p}$-value $(<0.05), \mathrm{PV}$ had the most prevalent mutation $(80 \%)$ this agrees with Baxter et al., (2005) [5] who reported that Jak2 mutation is present in hematopoietic cells in the vast majority of PV patients and that the difference in jak2 allele burden was highly significant between the PMNs disease entities.

Our study showed that the prevalence of Jak2 V617F mutation expression among MPNs patients was $50 \%$ and it was more prevalent in PV patients $(80 \%)$ than in both ET $(63.6 \%)$ and MF patients $(62.5 \%)$.

Despite this high expression of Jak2 mutation in $\mathrm{PV}$ and its relative lower expression in ET and MF it was found That Jak2 mutation expression was associated with increased risk of CMPNs including PV, ET and MF, and that this mutation is a risk factor for these disorders to develop.

In approval with these findings and owing to strong association between the Jak2 mutation and MPNS, the WHO now includes the Jak2 mutation among their major diagnostic criteria for PV, ET and CIMF. [15]

in another study it was found that detection of Jak2 mutation establishes the presence of clonal disorder and so Jak2 mutation should be performed as a front-line screening test for suspected MPNs and this may spare suspected patients further investigation. [9]

The difference in the reported rates may be due to difference in precision and sensitivity of methods used, e.g. direct sequencing used in some studies has lower sensitivity than techniques using PCR amplification. [16]

In addition earlier studies indicated that Jak2 mutation burden decreases with successful myelo suppressive therapy and may disappear in some patients and reappear on relapse, so quantitative Jak2 V617F may be useful not only in diagnosis but also in follow up and management. [17] In cases of MPNs with negative JAK2-V617F other mutations should be studied e.g. Other JAK2 mutations or translocations and/or MPLW515L mutation.

Other mutations and translocations should be studied in JAK2 V617F negative MPNs: 1-
JAK2 exon 14 other than JAK2 V617F such as $611,616,620$ and 627 mutations.

2- JAK2 exon 12 mutations which are clustered in 537 to $543 \mathrm{~B}$.

3- JAK2 fusion genes which are involved in myeloid and lymphoid leukemias and include PCM1-JAK2, BCR-JAK2, TEL/ETV6-JAK2.

4- MPLW515 Mutations in JAK2 V617F-negative ET and CIMF. [18]

JAK2 exon 12 mutations compared with JAK2 V617F is characterized by lower TLC and PLT count with higher $\mathrm{Hb}$ values, screening for exon 12 mutations in JAK2 V617F negative patients with clinical PV, unexplained erythrocytosis, venous thrombosis or Budd-Chiari syndrome may be helpful for establishing diagnosis. [3]

Compared with JAK2 mutations, JAK2 fusions are associated with more aggressive courses as AML, ALL, atypical CML and CIMF, e.g. pericentriolar material 1 (PCM1)-JAK2 fusion gene is found in atypical CML, CIMF CEL, AML and ALL. [19]

In November 2011, the JAK1/JAK2 inhibitor, ruxolitinib (Jakafi), became the first US Food and Drug Administration (FDA)-approved drug for patients with intermediate- or high-risk myelofibrosis, including primary myelofibrosis, post-polycythemia vera myelofibrosis, and postessential thrombocythemia myelofibrosis. Results showed patients $(n=309)$ who received ruxolitinib had a significant reduction in spleen volume (at least 35\%) at 24 weeks when assessed by MRI or CT compared with placebo. So more studies on Jak2 inhibitors should be continued for other CMPNs specially those positive for other JAK2 mutations or translocations. [20]

\section{REFERENCES}

1- Vardiman JW. (2002): The World Health Organization (WHO) classification of the myeloid neoplasms. Blood; 100:2299-2300.

2- Amy V. Jones, Sebastian Kreil, Katerina Zoi, Katherine Waghorn, Claire Curtis, Lingyan Zhang, Joannah Score, et al. (2005): Widespread occurrence of the JAK2V617F mutation in chronic myeloproliferative disorders. Blood ; 106: 2162-2168

3- Scott LM, Tong W, Levine RL, Scott MA., et al. (2007): JAK2 exon 12 mutations in polycythemia vera and idiopathic erythrocytosis.: N Engl J Med; 1,356(5):459468.

4- Ross L. Levine and Gerlinde Wernig. (2006): Role of JAK-STAT Signaling in the Pathogenesis of Myeloproliferative Disorders. The American Society of Hematology, 2006. Hematology. 
5- Baxter EJ, Scott LM and Campbell PJ. (2005): Acquired mutation of the tyrosine kinase JAK2 in human myeloproliferative disorders. Lancet; 365(9464):1054-1061.

6- Matthaios S., Eirini K., Chrisoula D., Eudokia M., Emmanouil P., Anna K., Konstantinos R., Ioannis K. (2007): Correlations of JAK2V617F mutation with clinical and laboratory findings in patients with myeloproliferative disorders. Leukemia Research; 31 1053-1062

7- Sidon P, EL Housini H, Dessars B, Heimann P. (2006): the JAK2 V617F mutation is detectable at very low levels in peripheral blood of healthy donars. Leukemia; 20:1622.

8- Kralovics R, Passamonti F, Buser AS, et al (2005): A gain-function mutation of JAK2 in myeloproliferative disorders. $\mathrm{N}$ Engl J Med; 352: $1779-1790$

9- James C, Ugo V, Le Couedic JP, et al. (2005): A unique clonal JAK2 mutation leading to constitutive signalling causes polycythaemia vera. Nature; 434(7037):1144-8.

10- Vardiman J. W. et al. (2009): The 2008 revision of the WHO classification of myeloid neoplasms and acute leukemia: rationale and important changes. Blood; 114, 937-951.

11- Levine RL, Belisle C, Wadleigh $\mathrm{M}$, et al. (2006): X-inactivation based clonality analysis and quantitative JAK2V617F assessment reveals a strong association between clonality and JAK2V617F in PV but not ET/MMM, and identifies a subset of JAK2V617F negative ET and MMM patients with clonal hematopoiesis. Blood; 107:4139-4141.

12- Levine RL, Loriaux M, Huntly BJ, et al. (2005): The JAK2V617F activating mutation occurs in chronic myelomonocytic leukemia and acute myeloid leukemia, but not in acute lymphoblastic leukemia or chronic lymphocytic leukemia. Blood; 106:3377-3379.

13- Bousquet M, Quelene M, De Mas V, et al. (2005) the $t(8-9)(p 22 ; p 24)$ translocation in atypical CML yeilds a new PCM1-JAK2 fusion gene. Oncogene; 24: 7248-7242

14- Villeval JL., James C., Pisoni DF., Casadevall N., Vainchenker W. (2006): New insights into the pathogenesis of Jak2 V617F positive MPDs \& consequences for the management of patients. Semin thromb Haematol; 32: 341351.

15- Tefferi A. and Vardiman JW. (2008): Classification and diagnosis of myeloproliferative neoplasms: the 2008 WHO criteria and point of care diagnosis algorithms. Leukemia; 22: 14-22.

16- Campbell P.J., Scott L.M., Baxter E.J., Bench A.J., Green A.R., and Erber W.N. (2006) :Methods for detection of the Jak2 V617F mutation in human myeloproliferative disorders. Methods in Molecular Medicine, 125: 253-264.

17- Kroger N., Badbaran A., Holler E, et al. (2007): Monitoring of the Jak2 V617F mutation by highly sensitive quantitative RealTime PCR after allogenic stem cell transplantation in patients with myelofibrosis. Blood; 109: 1361-1371.

18- Jones A.V., Kreil S., Xoi K., et al. (2005): wide spread of JAK2 V617F mutation in CMPD, Blood; 106: 2162-2168.

19- Murati A, Gelsi-Boyer V, Adelaide J, et al. (2006): PCM1-JAK2 fusion in myeloproliferatve disorders and acute erythroid leukemia with $\mathrm{t}(8 ; 9)$ translocation. Leukemia; 20:1319-1321.

20- Passamonti F. (2011): How to manage polycythemia vera. Leukemia ; 165-170. 